\title{
AVALIAÇÃO, ATITUDES, CRENÇAS LINGUÍSTICAS E O ENSINO DE LÍNGUA PORTUGUESA: UMA REFLEXÃO A PARTIR DE TESTES COM PROFESSORES DE ENSINO MÉDIO ${ }^{1}$
}

\author{
EVALUACIÓN, ACTITUDES, CREENCIAS LINGÜÍSTICAS \\ Y ENSEÑANZA DE LENGUA PORTUGUESA: UNA REFLEXIÓN BASADA EN \\ EXÁMENES CON PROFESORES DE LA SECUNDARIA
}

LINGUISTIC EVALUATION, ATTITUDES, BELIEFS

AND PORTUGUESE TEACHING: A REFLECTION BASED ON TESTS WITH HIGH SCHOOL TEACHERS

\author{
Rafaela Regina GHESSI ${ }^{2}$ \\ Rosane de Andrade BERLINCK ${ }^{3}$
}

RESUMO: A avaliação, as atitudes e crenças linguísticas suscitam a construção de julgamentos subjetivos do falante sobre sua própria língua e do seu interlocutor. Tais julgamentos podem influenciar o quadro de variação ou o curso de processos de mudança, estando, usualmente, ancorados na ideologia linguística de uma língua padrão. No ambiente escolar, destaca-se o professor como um dos agentes principais do que é transmitido e/ou reforçado no processo de ensino-aprendizagem. Por seu papel no processo de construção de crenças e atitudes, propusemos neste estudo investigar atitudes linguísticas de professores de duas escolas públicas de Monte Azul PaulistaSP, quanto ao fenômeno variável de concordância verbal, de modo a auxiliar na discussão sobre a valorização ou rejeição às variedades linguísticas em uso e sobre o ensino de língua portuguesa no Brasil. Este trabalho pautou-se na abordagem teóricometodológica da Sociolinguística Variacionista (WEINREICH; LABOV; HERZOG, 2006; LABOV,2008).

PALAVRAS-CHAVE: Atitude linguística. Avaliação linguística. Concordância verbal. Teste de atitudes linguísticas. Teoria da variação e mudança linguística.

RESUMEN: La evaluación, las actitudes y las creencias lingüísticas fomentan la construcción de juicios subjetivos del hablante sobre su propio idioma y el de su interlocutor. Tales juicios pueden influir en el marco de variación o en el curso de los procesos de cambio, y generalmente están anclados en la ideología lingüística de un

\footnotetext{
${ }^{1}$ Este artigo se baseia em discussões e resultados da Dissertação de Mestrado "Concordância verbal em português: um estudo sobre atitudes linguísticas em duas escolas públicas de Monte Azul Paulista-SP.", da primeira autora, particularmente de seu capítulo 4.

${ }^{2}$ Universidade Estadual Paulista (UNESP), Araraquara - SP - Brasil. Mestranda no Programa de PósGraduação em Linguística e Língua Portuguesa. ORCID: https://orcid.org/0000-0003-3816-111X. Email: rafaela.rghessi@gmail.com

${ }^{3}$ Universidade Estadual Paulista (UNESP), Araraquara - SP - Brasil. Doutora. Professora Assistente. Departamento de Linguística, Literatura e Letras Clássicas. Doutorado em Linguística pela Katholieke Universiteit Leuven - Bélgica. ORCID: https://orcid.org/0000-0003-3420-5541. E-mail: rosane.berlinck@unesp.br
} 
lenguaje estándar. En el entorno escolar, se destaca el profesor como uno de los principales agentes de lo que se transmite y/o se refuerza en el proceso de enseñanzaaprendizaje. Debido a su papel en el proceso de construcción de creencias y actitudes, este estudio objetiva investigar las actitudes lingüísticas de los profesores de dos escuelas públicas en la ciudad de Monte Azul Paulista-SP, con respecto al fenómeno variable de la concordancia verbal, para contribuir con la discusión sobre la valorización o el rechazo a las variedades lingüísticas en uso y sobre la enseñanza del portugués en Brasil. Este trabajo se fundamenta en el enfoque teórico-metodológico de la Sociolingüística Variacionista (WEINREICH; LABOV; HERZOG, 2006; LABOV, 2008).

PALABRAS CLAVE: Actitud lingüística. Evaluación lingüística. Concordancia verbal. Test de actitudes lingüísticas. Teoría de la variación y cambio lingüístico.

ABSTRACT: Evaluation, attitudes and linguistic beliefs led to subjective judgments of the speaker about his own language and that of his interlocutor. Such judgments can influence linguistic variation or the course of linguistic change, and are usually anchored in the ideology of a standard language. In the school environment, the teacher stands out as one of the main agents of what is transmitted and / or reinforced in the teaching-learning process. Due to its role in the process of building beliefs and attitudes, we proposed in this study to investigate the linguistic attitudes of teachers from two public schools in Monte Azul Paulista-SP, regarding the variable phenomenon of verbal agreement. The main objective is to discuss about the valorization or rejection to the linguistic varieties in use and about the teaching of Portuguese in Brazil. This work was based on the theoretical and methodological approach of Variationist Sociolinguistics. (WEINREICH; LABOV; HERZOG, 2006; LABOV,2008).

KEYWORDS: Linguistic attitude. Linguistic evaluation. Verbal agreement. Attitude measurement techniques. Theory of Language Variation and Change.

\section{Introdução}

A avaliação é uma questão que deve ser necessariamente discutida em estudos sobre variação e mudança linguística, pois suscita um processo de construção de julgamentos subjetivos do falante em relação a sua própria língua e à do seu interlocutor, e porque tais julgamentos podem influenciar o quadro de variação ou o curso de processos de mudança. Esses julgamentos estão ancorados na ideologia linguística de uma língua padrão, uma vez que os falantes acreditam que "as línguas existem em formas padronizadas, e esse tipo de crença afeta o modo como pensam sua própria língua e a ‘língua’ em geral” (MILROY, 2011, p. 49).

A concepção social de padronização da língua reflete-se no ensino de Língua Portuguesa nas escolas brasileiras e nos livros didáticos adotados pelos professores: 
embora apresentem variação linguística como conteúdo, aparentemente a concepção de língua como prática social não está subjacente à sua abordagem ${ }^{4}$. A escola, que poderia (deveria) ser um espaço de reflexão sobre a língua e de construção do respeito à diversidade, acaba sendo um ambiente propício para a distorção da realidade linguística e propagação de preconceitos linguísticos, silenciando sujeitos externos a uma norma idealizada $^{5}$, que é carregada de ideologias e de relações de poder (PETERMANN; ALVES, 2018).

O estudo das avaliações e atitudes linguísticas é uma das tarefas a que a Sociolinguística se propõe, sendo uma das questões fundadoras da Teoria da Variação e Mudança Linguísticas. Weinreich, Labov e Herzog (2006 [1968]) afirmam que avaliações inconscientes sobre falantes de um certo subsistema linguístico determinariam o significado social que se atribuiria ao emprego dessa variedade. E, desse modo, influenciariam sua possível expansão ou desaparecimento.

Assim, os trabalhos que discutem a rejeição da escola à variedade do aluno são de suma importância e devem ser elaborados sob a ótica da língua como prática social. Compreender e analisar as atitudes de professores e alunos abre caminhos para a discussão da variação e mudança dentro do universo escolar, orientando para um ensino que considera o aluno como um indivíduo pensante e ativo e não mais aquele que "não sabe português". Uma nova pedagogia de ensino de língua materna pauta-se em um trabalho sem danos aos valores sociais dos alunos.

Defendemos que os alunos precisam ter consciência de que a língua varia com o tempo e que todas as variedades, do ponto de vista estrutural linguístico, são perfeitas e equivalentes entre si. A escola não pode ignorar as diferenças sociolinguísticas. Deve-se usá-las para que os alunos reflitam sobre a variedade que adquirem em casa e as variedades cultas, que aprendem na escola; assim será possível desenvolver sua competência comunicativa ${ }^{6}$ tanto na modalidade falada como na escrita.

${ }^{4}$ Em sua análise de livros didáticos do Ensino Médio, Petermann e Alves (2018) concluíram que a abordagem de ensino desses livros mais visa ao "reconhecimento e classificação das "variedades" do que a reflexão acerca da existência e da persistência dos fenômenos linguísticos" e enxergam a variação linguística como "distorções de um padrão ilusório da língua" (PETERMANN; ALVES, 2018, p. 19).

${ }^{5}$ Faraco (2008) propõe um tratamento para a polissemia que envolve a concepção de norma. Norma culta/comum/standard é a "variedade que os letrados usam correntemente em suas práticas mais monitoradas de fala e escrita" (FARACO, 2008, p. 73), enquanto norma-padrão é uma "codificação relativamente abstrata, uma baliza extraída do uso real para servir de referência, em sociedades marcadas por acentuada dialetação, a projetos políticos de uniformização linguística".

${ }^{6}$ Entendemos que a competência comunicativa inclui "[...] não só as regras que presidem à formação das sentenças, mas também as normas sociais e culturais que definem a adequação da fala" às diferentes situações de comunicação (BORTONI-RICARDO, 2004, p. 73). 
Partindo dessas reflexões e sob os pressupostos teórico-metodológicos da Sociolinguística Variacionista (WEINREICH; LABOV; HERZOG, 2006 [1968]; LABOV, 2008 [1972]), o objetivo principal deste trabalho é investigar as atitudes linguísticas de professores de Língua Portuguesa do Ensino Médio de duas escolas da rede pública de Monte Azul Paulista- SP, em relação ao fenômeno variável de concordância verbal $(\mathrm{CV})$ de terceira pessoa do plural. Para tanto, elaboramos um teste de atitudes linguísticas ${ }^{7}$ que foi aplicado aos professores de Língua Portuguesa, e cujo detalhamento virá exposto na seção de Procedimentos metodológicos.

A escolha da CV é justificada por ser um fenômeno superavaliado. Temos duas variantes - a ausência da marcação de plural nos verbos (Os meninos fala $\varnothing$ ) e a presença de marcação de plural nos verbos (Os meninos falam) -, o que significa dizer que a informação de pluralidade está assegurada nos dois casos. No entanto, a não realização do traço morfológico de número possui um valor sociolinguístico, podendo corresponder a uma maneira de desqualificar o falante da língua. Sobre isso, Scherre (2005) argumenta:

Quem deixa de fazer concordância de número é normalmente chamado de burro, ignorante, porque, afirma-se, "não saber falar". Somos então às vezes inteligentes e às vezes burros? Somos "variavelmente" inteligentes? Repito: a variação da concordância de número no português brasileiro está seguramente instalada na língua falada [...]. (SCHERRE, 2005, p. 20).

Antes de apresentarmos a proposta do teste e analisarmos seus resultados, cabe aprofundar os conceitos de avaliação, crença e atitudes linguísticas.

\section{Avaliação, atitudes e crenças linguísticas}

A problemática das atitudes e crenças linguísticas se insere no âmbito de um dos problemas empíricos propostos pela Teoria da Variação e Mudança Linguística (WEINREICH; LABOV; HERZOG, 2006 [1968]). - o problema da avaliação das variáveis linguísticas. De acordo com Labov (2008 [1972]), “[n]em todas as mudanças linguísticas recebem avaliação social explícita ou sequer reconhecimento. Algumas parecem ficar muito abaixo do nível das reações sociais explícitas” (p. 354). Para o autor (2008 [1972), é possível classificar os diversos elementos envolvidos na variação

${ }^{7} \mathrm{O}$ teste de atitudes linguísticas é uma adaptação de Barbosa e Ghessi (2019), pesquisa aprovada pelo Comitê de Ética (Protocolo 2112) da Universidade Federal do Triângulo Mineiro (UFTM). 
e mudança linguística segundo sejam ou não avaliados e, em caso afirmativo, segundo o tipo de avaliação social que eles recebem. Distingue, assim, três tipos de variáveis: indicadores, marcadores e estereótipos.

Os primeiros são traços linguísticos encaixados em uma matriz social, indicando diferenciação entre os falantes, mas que não possuem nenhum padrão de alternância estilística e não possuem muita força avaliativa. Os marcadores, embora possam estar abaixo do nível da consciência, produzem reações regulares em testes de reações subjetivas, possuindo mais força avaliativa que os indicadores (LABOV, 2008 [1972], p. 360). Por último, os estereótipos "são formas socialmente marcadas, rotuladas enfaticamente pela sociedade" (LABOV, 2008 [1972], p. 360).

Algumas formas podem ter prestígio que varia de grupo para grupo, sendo, dessa forma, positivos para alguns e negativos para outros. As variantes linguísticas que recebem mais força avaliativa tornam-se mais facilmente identificadas, fazendo com que os falantes passem a monitorar sua fala com o objetivo de não serem avaliados. A avaliação linguística diz respeito à forma como um ouvinte/falante mensura os valores que carrega consigo, associando esses valores à sua própria produção linguística e àquela de seus interlocutores.

A relação entre avaliação e atitudes se coloca, então, naturalmente, na medida em que o estudo da avaliação busca compreender os correlatos subjetivos do quadro de variação e das mudanças linguísticas em curso. Nas palavras de Lambert e Lambert (1972):

Uma atitude é uma maneira organizada e coerente de pensar, sentir e reagir em relação a pessoas, grupos, questões sociais ou, mais genericamente, a qualquer acontecimento ocorrido com nosso meio circundante. Seus componentes essenciais são os pensamentos e as crenças, os sentimentos (ou emoções) e as tendências para reagir. (LAMBERT; LAMBERT, 1972, p. 77-78).

Assim, afirma-se que se integram nas atitudes três componentes: o cognitivo, o afetivo e o comportamental ${ }^{8}$ (LAMBERT; LAMBERT, 1972; RODRIGUES, 1972; entre outros). Ou seja, para que uma atitude se constitua, são necessários esses três componentes inter-relacionados, de forma que, "aquilo que se sente e a maneira como se reage diante de um objeto social estejam coerentemente associados ao modo como se pensa a respeito dele." (BOTASSINI, 2015, p. 114).

${ }^{8}$ Critérios dos defensores de uma interpretação mentalista da atitude. 
O componente cognitivo diz respeito às crenças que o falante tem em relação a um objeto social referido, pois "Não se pode ter uma atitude em relação a um objeto se não houver alguma representação cognitiva a seu respeito, ou seja, é preciso conhecê1o" (BOTASSINI, 2015, p. 115). Desse modo, atitudes preconceituosas são resultados de cognições negativas em relação ao grupo ou variedade que está sendo objeto de discriminação (RODRIGUES, 1972, p. 398).

O componente afetivo refere-se às emoções e aos sentimentos pró ou contra um objeto social, sendo mais relacionado à valoração do sujeito, característica das atitudes sociais. Por fim, temos o componente comportamental ou conativo, entendido como reação ou conduta diante de um objeto social.

As crenças e as avaliações linguísticas são, portanto, parte fundamental da atitude e dizem respeito àquilo em que os indivíduos acreditam, pensam, sentem a respeito de algo. Um aspecto essencial da natureza das crenças (e das avaliações), destacado por Barcelos e Abrahão (2006, p. 19), é o fato de que "nascem no contexto da interação e na relação com os grupos sociais, incorporando as perspectivas sociais". Desse modo, são "[e]mergentes, socialmente construídas e situadas contextualmente. (BARCELOS; ABRAHÃO, 2006, p. 19; grifo dos autores). Esse aspecto é fundamental, porque nos põe diante de uma realidade que muda e que pode ser mudada, o que abre espaço para uma reflexão sobre o papel da escola nesse processo.

Tendo em conta a estreita relação entre crenças e atitudes, assumimos neste trabalho que atitudes linguísticas incluem uma atividade, uma reação e/ou exteriorização do que se pensa, do que se avaliou enquanto se pensava. Também entendemos que as crenças sobre a língua são construídas por meio das experiências vivenciadas no contexto social e ao longo dos anos de aprendizagem no contexto escolar. Destaca-se no ambiente escolar o professor, como um dos agentes principais do que é transmitido e/ou reforçado na escola. Por seu papel fundamental no processo de construção de crenças e atitudes é que propusemos elaborar e aplicar testes de atitudes linguísticas a professores de duas escolas públicas de Ensino Médio.

O trabalho dessa natureza no contexto escolar tem como um dos grandes desafios a reconstrução do imaginário sobre a língua; busca-se acessar o que se passa na mente dos professores. Os testes se propõem como um instrumento para nos aproximarmos desse imaginário, de modo a observar que conjunto de ideias circula no cenário de formação dos alunos. Conhecer é necessário para mudar. 


\section{Procedimentos metodológicos}

Como já foi exposto, o objetivo deste trabalho é observar as atitudes de professores de duas escolas públicas no que se refere às convenções e aos padrões institucionalizados, de modo a nos auxiliar na discussão da valorização e rejeição às variedades da língua em uso ${ }^{9}$. O fenômeno variável da concordância verbal de terceira pessoa do plural foi colocado na dimensão avaliativa, já que é a partir dele que verificamos, neste trabalho, nos testes de atitudes linguísticas, as reações positivas e negativas dos professores. Ressaltamos, portanto, que nessa pesquisa entendemos atitudes linguísticas como uma disposição valorativa dos falantes sobre os fenômenos linguísticos, no nosso caso, sobre a concordância verbal.

$\mathrm{O}$ teste de atitudes linguísticas foi aplicado a quatro professores de língua portuguesa de duas escolas públicas de Monte Azul Paulista - SP. Esta análise faz parte de um estudo mais amplo que incluiu a investigação das atitudes linguísticas de alunos da mesma escola (GHESSI, 2020). Os professores que participaram da pesquisa são os professores de língua portuguesa dos alunos participantes e as respostas de ambos os grupos foram correlacionadas no estudo do qual este é um recorte. Se levarmos em conta apenas o universo de professores envolvidos, seria mais adequado considerar que temos aqui um estudo piloto sobre suas atitudes.

Na construção do teste, selecionamos amostras de trechos narrativos distintos, que representam escritas com graus de monitoramento diferentes em relação à norma culta: um fragmento mais próximo da norma culta e outro mais distante, com características do que se considera fora da norma culta (com ausências de concordâncias verbais, poucos mecanismos de coesão, etc). Tais fragmentos foram retirados de redações de alunos de escola pública da cidade de Uberaba-MG, recolhidas na pesquisa de Iniciação Científica financiada pela FAPEMIG/BIC, intitulada "Padrões variáveis de concordância verbal de terceira pessoa do plural em redações escolares do $3^{\circ}$ ano do Ensino Médio da cidade de Uberaba" ${ }^{" 10}$. Observamos a seguir os fragmentos:

(I) Eles permaneceram lá por 45 dias e passaram por muitos lugares, muitas cidades e conheceram um pouco da cultura de cada um. É claro que eles perceberam que muitas coisas são diferentes dos costumes que temos aqui no Brasil, mas, mesmo assim ficaram

${ }^{9} \mathrm{O}$ estudo mais amplo de que este é um recorte inclui também a investigação de atitudes linguísticas de alunos das mesmas escolas.

${ }^{10}$ Aprovado pelo Comitê de Ética (Protocolo 2112) da Universidade Federal do Triângulo Mineiro (UFTM). 
encantados com tudo o que puderam presenciar naqueles lugares. [Emprestado da pesquisa de IC fomentado pela FAPEMIG]

(II) Chegando em seu destino, desceram e prosseguiu até a casa da amiga. Chegando lá todos sentou e conversou, até que a mãe de sua amiga lhe ofereceram para eles almoçar. Todos almoçou, lavou às louças, então decidiram ir todos para a casa. [Emprestado da pesquisa de IC fomentado pela FAPEMIG]

A escolha desses fragmentos se justifica pelo conjunto de suas características linguísticas e pelo fato de já terem sido utilizados com sucesso em outra pesquisa ${ }^{11}$, o que demonstrou sua adequação para os objetivos propostos. O fato de nos valermos de fragmentos escritos se justifica também por serem poucos os trabalhos sobre atitudes linguísticas que utilizam estímulos de materiais dessa modalidade, apesar de o domínio da escrita ser um dos objetivos centrais do ensino de língua portuguesa. Esse constitui, portanto, um traço inovador desta pesquisa. Evidenciamos aqui, assim como Barbosa e Cuba (2015), Barbosa e Ghessi (2019), que é possível depreender reações positivas e negativas em testes de atitudes linguísticas que utilizam textos escritos.

Das duas abordagens diferentes que compõem testes de atitudes - a abordagem direta e a técnica do diferencial semântico (OSGOOD; SUCI; TANNENBAUM, 1957), nos restringimos neste trabalho a apresentar a primeira abordagem,. Nela utilizamos um questionário convidando os professores a darem respostas abertas e escritas sobre o objeto selecionado para a avaliação.

O objetivo das perguntas é conseguir observar se os professores citam a concordância verbal como sendo o fenômeno que diferencia um fragmento do outro e, assim, conseguir depreender avaliações sobre o uso da concordância nas duas formas possíveis. Além disso, buscamos também compreender a opinião do professor de língua portuguesa, participante da pesquisa, acerca da variação linguística, analisando sua avaliação sobre os “desvios" presentes em um dos fragmentos e suas possíveis ações (ou práticas) docentes em sala de aula em relação a esses desvios.

O método de coleta de dados para a constituição do corpus envolve o contato entre o pesquisador e indivíduos/comunidades, dessa forma, este trabalho foi submetido ao Comitê de Ética em Pesquisa (CEP), subordinado à CONEP (Ministério da Saúde) Parecer CEP 2.750.849.

${ }^{11}$ Barbosa e Ghessi (2019). 


\section{Análise dos dados}

A partir de sua análise dos dois fragmentos distintos, um com presença da $\mathrm{CV}$ e outro com ausência, pediu-se aos professores que respondessem às seguintes perguntas: (i) "É possível identificar se os trechos são escritos por pessoas diferentes? Justifique"; (ii) "É possível ver diferenças entre os dois trechos? Aponte algumas."; (iii) Um texto/fragmento é melhor que o outro? Justifique"; (iv) Se produzido por seus alunos, qual avaliação receberiam tais textos? Explique".

As respostas dadas nos levaram a constatar duas crenças principais dos docentes: (a) a crença de que existem falantes de estilo único (LABOV, 2008[1972]); e (b) a crença do erro linguístico. Em relação à primeira crença, os professores caracterizaram os fragmentos pela dicotomia formalidade $\mathrm{X}$ informalidade, sem conceberem o jogo discursivo das relações sociais envolvidas no evento comunicativo, como observamos nesses excertos de suas respostas:

(01) A mesma pessoa não se utilizaria de registros tão distintos um do outro. [PROF_A_01F].

(02) Os dois fazem uso de registros bem diferentes em relação à formalidade/informalidade dos textos. [PROF_A_02F].

(03) O texto II possui frequentes erros de concordância, que sugere uma linguagem coloquial, diferente da apresentada no texto $I$. [PROF_B_02M].

No excerto (01), vemos que, para a professora, a mesma pessoa não utilizaria registros tão distintos um do outro, desconsiderando, dessa forma, a heterogeneidade do sistema linguístico. Labov (2008 [1972]) observa que não existem falantes de estilo único, uma vez que está à disposição dos usuários da língua um campo vasto de alternâncias estilísticas. Todos os alunos que chegam à escola já são usuários competentes da sua língua materna, mas precisam ampliar seus recursos comunicativos para poder atender às convenções sociais, "que definem o uso linguístico adequado a cada gênero textual, a cada tarefa comunicativa, a cada tipo de interação" (BORTONIRICARDO, 2004, p. 74). O informante, com essa resposta, revela uma concepção de língua que está desassociada da pedagogia da variação linguística.

Em (02), assim, como no excerto anterior, a docente também revela acreditar que ou o falante domina a norma culta ou faz uso de variedades desprestigiadas, e que há uma correlação direta entre duas dicotomias - por um lado, "norma culta" e 
"formal"; por outro, "variedade desprestigiada" e "informal". Assim, os professores acabaram caracterizando os fragmentos pela dicotomia redutora da formalidade/informalidade, sem considerar o jogo discursivo das relações sociais envolvidas no evento comunicativo.

A variabilidade linguística se torna naturalmente intrínseca a cada falante, pelo fato de sua vida social e cultural ser diversificada. O usuário da língua vai construindo, por meio de suas vivências em diferentes práticas sociais, um repertório linguístico variado, dominando vários registros da língua. A realidade heterogênea característica de toda língua e sociedade é imensamente dinâmica, isto é, as variedades linguísticas passam por mudanças lentas e contínuas e vão se alterando à medida que a sociedade vai mudando. Apesar disso, a ideologia do "erro" linguístico e da língua-padrão costuma atuar sob uma concepção idealizada e impositiva de imutabilidade e estaticidade, como podemos observar com a resposta do informante PROF_B_02M, em 03. De acordo com Bortoni-Ricardo (2004):

Erros de português são simplesmente diferenças entre variedades da língua. Com frequência, essas diferenças se apresentam entre a variedade usada no domínio do lar, onde predomina uma cultura de oralidade, em relações permeadas pelo afeto e informalidade [...] e culturas de letramento, como a que é cultivada na escola (BORTONIRICARDO, 2004, p. 37, grifo do autor).

Todo falar é, antes de tudo, um instrumento identitário, dessa forma, é pedagogicamente incorreto usar o discurso do "erro" como uma oportunidade para humilhar ou desvalorizar a fala do educando. Da perspectiva de uma pedagogia culturalmente sensível, diante da realização de uma regra "não-padrão", o professor deve, primordialmente, conscientizar os alunos da diferença para que possam ampliar seus recursos comunicativos e, dessa forma, conseguirem monitorar seu próprio estilo, mas isso tem que ser feito com respeito às características culturais que eles carregam. Vale salientar que o professor PROF_B_02M (excerto 03) afirma que os "erros de concordância" sugerem uma linguagem coloquial, retomando, mais uma vez, a problemática da dicotomia entre formalidade/informalidade.

A noção do "erro" linguístico foi bastante recorrente nas respostas dos professores, sugerindo que a concepção de língua que perpassa a instituição escolar está dissociada da concepção de língua heterogênea, variável e dinâmica (LABOV, 2008 [1972]). Os excertos a seguir também evidenciam o imaginário do Certo X Errado: 
(04) o texto I apresenta uma organização coerente de ideias, com o uso correto das regras de concordância, pontuação, coesão, entre outros. O texto II, ao contrário, apresenta uma deficiência muito grande em todos esses quesitos. [PROF_A_02F].

(05) Normalmente faço uma correção individual com o aluno para não expô-lo ou constrangê-lo e, algumas vezes, uso o texto com tais erros para trabalhar com a sala, fazendo as devidas correções e adequações, isso se o aluno permitir/autorizar o uso de seu texto, sem a revelação de seu nome, é claro. Esta é a forma de reflexão sobre o erro para os demais alunos. [PROF_A_02_F].

(06) Apontaria os erros no texto II com breve explicação sobre concordância [...]. [PROF_B_02M] (Grifos nossos).

A língua é recoberta de um imaginário que nos orienta como devemos dar sentido às variedades linguísticas, estabelecendo o que é valor e o que não é. Assim, os falantes acreditam que podem censurar o comportamento linguístico dos outros, afirmando que determinadas variedades constituem formas "erradas" de falar a língua, a partir de uma concepção normativa que pressupõe que há diferenças qualitativas entre as variedades. Sobre esse aspecto, os Parâmetros Nacionais Curriculares (PCNs) orientam que: "A questão não é de erro, mas de adequação às circunstâncias de uso, de utilização adequada da linguagem" (BRASIL, 1998, p. 31).

A menção ao uso ou não da concordância como uma diferença entre os fragmentos, vista nos excertos (03), (04) e (06), já era esperada, principalmente considerando o estigma social que a ausência da marcação da CV carrega. Tais respostas evidenciam o valor social que a variante sem a marca explicita de plural carrega dentro da sociedade. No entanto, sabemos que a não marcação de plural não modifica o sentido dos enunciados. A ausência ou a presença morfológica ("Os meninos fala $\varnothing$ vs Os meninos falam) "sinaliza variedades, registros e modalidades diversos, que, em conjunto, constituem uma complexa rede variável e configuram genericamente uma característica do Português do Brasil” (VIEIRA; PIRES, 2012, p. 169).

Além das duas crenças reveladas nas respostas dos professores - "o falante de estilo único" e o "erro linguístico" -, também conseguimos observar a atribuição de valor de "superioridade" de um fragmento em relação ao outro. É o que se vê nos excertos (07) a (09):

(07) Diria que o trecho I segue normas de concordância, regência, pontuação, ortografia de forma mais competente em relação o 
segundo trecho, o que proporciona um melhor entendimento devido à coesão estabelecida e sua coerência. [PROF_A_01F].

(08) Ambos os textos transmitem as mensagens com clareza, porém o texto II apresenta erros. Assim, podemos considerar o texto I "superior". [PROF_B_02M].

(09) O primeiro trecho receberia uma melhor "nota", porém nunca atribui essas notas de forma pública. Costumo fazer um registro pessoal e, no texto, coloco orientações a respeito de como o aluno deve proceder ao refletir sobre sua produção textual e a melhoria das condições de sua própria correção na reescrita ou futuras produções. [PROF_A_01F].

Em relação ao excerto (07), a reação da professora pode não ser apenas o reflexo de suas atitudes sobre os fenômenos linguísticos postos em avaliação, mas pode incluir também um conjunto de atitudes relativas às qualidades do usuário da língua. Quando a professora se refere ao trecho I como "mais competente", está, metonimicamente, avaliando o produtor do texto. Os questionamentos a serem feitos são "o que é ser mais competente?" e "como podemos avaliar a competência de um falante por meio de um (único) texto?".

Já vimos que todos os alunos que chegam à escola são usuários competentes da sua língua materna, cabendo à escola "criar condições para que os educandos desenvolvam sua competência comunicativa" (BORTONI- RICARDO, 2004, p. 78). Assim, o uso da palavra "competente" para diferenciar um fragmento do outro vem carregado de valores negativos em relação à língua, mas principalmente ao usuário dela.

O PROF_B_02M, em (08), considera o fragmento I "superior" ao fragmento II por não possuir "erros". A Sociolinguística vem demonstrando que, pelo ponto de vista estrutural, todas as formas e variedades linguísticas são equivalentes, pois "todas as formas e variedades linguísticas têm uma organização estrutural (uma gramática), embora só algumas recebam a qualificação de corretas" (FARACO, 2008, p. 136). Com esse comentário feito pelo docente, depreendemos sua crença de que é dever da escola buscar uma normatização linguística, concentrando esforços no cultivo de um ideal de língua, isto é, "de um determinado conjunto de fatos de linguagem tidos como corretos" (FARACO, 2008, p. 135). O grande agravante de tudo isso é que a escola se torna um lugar onde se reforça intolerância linguística e preconceito, uma vez que os julgamentos valorativos sobre línguas se tornam ou revelam, também, julgamento sobre seus falantes. 
Além dessas reflexões, em (09) vemos que a PROF_A_01F daria a melhor nota para o fragmento que possui a presença da marca explícita de plural, provando que a CV faz parte dos requisitos básicos para uma avaliação positiva. De acordo com Vieira e Pires (2012, p. 183), "fica claro que, em uma matriz de elementos caracterizadores de um texto considerado bom em termos de padrão culto, a concordância verbal, ao que parece, constitui traço de alta saliência na avaliação da banca corretora do vestibular”.

Considerando as respostas obtidas dos professores, conseguimos perceber que nenhum docente possui uma prática pedagógica amparada na variação linguística, ou seja, não possuem estratégias de reflexão sobre a diversidade linguística. Pelo contrário, o que se vê é uma prática coerciva, que iguala reflexão a correção de 'erros', como fica explícito na fala, por exemplo, do PROF_A_02_F, em (05) - “uso o texto com tais erros para trabalhar com a sala, fazendo as devidas correções e adequações [...] Esta é a forma de reflexão sobre o erro para os demais alunos".

\section{Considerações finais}

No recorte da pesquisa apresentado neste artigo, vimos que o teste de atitudes nos permitiu verificar a aproximação do professor às convenções e aos padrões institucionalizados, corroborando com as pesquisas sobre esse fenômeno variável: a não realização do traço morfológico de número possui um valor sociolinguístico negativo e é utilizada como uma maneira de desqualificar o falante da língua.

As respostas mostraram que há imagens e significações que recobrem a língua e são reforçadas pela escola. Esse imaginário de hierarquização de um padrão, que cria estereótipos, está dentro de sala de aula e no imaginário dos professores. Os professores de língua materna deviam ser os agentes que desconstroem estereótipos linguísticos, mas o que se depreende é que há uma forte hesitação em se trabalhar a pluralidade da língua dentro de sala de aula, em parte por lacunas de formação. Embora o conceito de língua, como ela é e como ela funciona, já esteja bem descrito e fundamentado pelos linguistas, ainda não foi possível alterar atitudes e práticas linguísticas equivocadas na sociedade, nem mesmo no contexto educacional.

Defendemos que a escola pode vir a ser um ambiente de reflexão linguística e sem dano aos valores sociais dos alunos, porém temos a consciência de que temos um trabalho árduo pela frente, uma vez que estamos frente a crenças, estereótipos, conservadorismos, elitismo, poder e ideologias, que advêm do sistema colonial que nos 
constituiu e que, até hoje, possuem raízes férteis. Porém, como cientistas da linguagem e defensores de práticas linguísticas igualitárias, devemos resistir e persistir nesse caminho, levando a vários âmbitos sociais a nossa concepção sobre a língua, provada empiricamente. Não é mais possível observar a língua como sinônimo de gramática normativa, sem fazer qualquer referência à heterogeneidade do sistema linguístico; isso corresponderia a ignorar a essência multifacetada e diversificada que assegura sua funcionalidade.

AGRADECIMENTOS: As autoras agradecem ao CNPq pelo apoio financeiro que permitiu o desenvolvimento da pesquisa (Bolsa de Mestrado; Bolsa de Produtividade em Pesquisa - Proc. n. 308926/2016-1).

\section{REFERÊNCIAS}

BARBOSA, J. B.; GHESSI, R. R. Atitudes linguísticas e o ensino de língua portuguesa: uma reflexão sociolinguística. Tabuleiro de Letras, v. 13, p. 69-91, 2019.

BARBOSA, J.B.; CUBA, D.L. Crenças e Atitudes Linguísticas de Alunos do Ensino Médio em Escolas Públicas de Uberaba. Todas as Letras - Revista de Língua e Literatura, v. 17, n. 1, p. 73-90, 2015.

BARCELOS, A. M. F.; ABRAHÃO, M. H. V. Crenças e ensino de línguas: foco no professor, no aluno e na formação de professores. Campinas: Pontes, 2006.

BORTONI- RICARDO, S. M. Educação em língua materna: a sociolinguística na sala de aula. São Paulo: Parábola, 2004.

BOTASSINI, J. O. M. A importância dos estudos de crenças e atitudes para a sociolinguística. Signum: Estudos da Linguagem, Londrina, v. 18, n. 1, p. 102-131, 2015.

BRASIL. Ministério da Educação e do desporto. Parâmetros Curriculares Nacionais de Língua Portuguesa $-3^{\circ}$ e $4^{\circ}$ ciclos. Brasília, 1998.

FARACO, C. A. Norma culta brasileira: Desatando alguns nós. São Paulo: Parábola, 2008.

GHESSI, R. R. Concordância verbal em português: um estudo sobre atitudes linguísticas em duas escolas públicas de Monte Azul Paulista - SP. Orientadora: Rosane de Andrade Berlinck. 2020. 338 f. Dissertação (Mestrado em Linguística e Língua Portuguesa) - Universidade Estadual Paulista, Araraquara, 2020.

LABOV, W. Padrões Sociolinguísticos. São Paulo: Parábola Editorial, 2008[1972]. 
LAMBERT, W. W.; LAMBERT, W. E. Psicologia social. 3. ed. Rio de Janeiro: Zahar, 1972.

MARTINS, M. A; VIEIRA, S. R; TAVARES, M. A. (Orgs.). Ensino de português e sociolinguística. São Paulo: Contexto, 2014.

MILROY, J. Ideologias linguísticas e as consequências da padronização. In:

LAGARES, X. C.; BAGNO, M. Políticas da norma e conflitos linguísticos. São Paulo: Parábola, p. 49-87, 2011.

OSGOOD, C. E.; SUCI, G. I.; TANNENBAUM, P. H. The measurement of meaning. Illinois: University of Illinois Press, 1957.

PETERMANN, R., ALVES, L. H. Língua, variação e livro didático: análise da abordagem da variação linguística em manuais didáticos do Ensino Médio. LínguaTec, Bento Gonçalves, v. 3, n. 6, p. 01-21, nov. 2018.

RODRIGUES, A. Psicologia social. Petrópolis: Vozes, 2. ed. 1972.

SCHERRE, M. M. P. Doa-se lindos filhotes de poodle: variação linguística, mídia e preconceito. São Paulo: Parábola Editorial, 2005.

VIEIRA, S. R.; PIRES, J. C. P. Padrões variáveis de concordância verbal em redações de vestibular: restrições e avaliação. Matraga, Rio de Janeiro, v. 19, n. 30, p. 168-185, 2012.

WEINREICH, U.; LABOV, W.; HERZOG, M.I. Fundamentos empíricos para uma teoria da mudança linguística. Trad. Marcos Bagno. São Paulo: Parábola Editorial, 2006.

\section{Como referenciar este artigo}

GHESSI, Rafaela Regina; BERLINCK, Rosane de Andrade. Avaliação, atitudes, crenças linguísticas e o ensino de língua portuguesa: uma reflexão a partir de testes com professores de ensino médio. Rev. EntreLínguas, Araraquara, v. 6, n. 1, p. 108-122, jan./jun., 2020. e-ISSN: 2447-3529. DOI: https://doi.org/10.29051/el.v6i1.13270

Submetido em: 30/07/2019

Revisões requeridas: 30/08/2019

Aprovado em: 30/11/2019

Publicado em: 06/01/2020 